\title{
SUMO-1 delays neuronal damage in the spinal cord following ischemia/reperfusion
}

\author{
HYO YOUNG JUNG ${ }^{1 *}$, DAE WON KIM ${ }^{2 *}$, HYUN JUNG KWON ${ }^{2}$, DAE YOUNG YOO ${ }^{1}$, IN KOO HWANG ${ }^{1}$, \\ MOO-HO WON ${ }^{3}$, TACK-GEUN CHO ${ }^{4}$, SOO YOUNG CHOI ${ }^{5}$ and SEUNG MYUNG MOON ${ }^{6}$ \\ ${ }^{1}$ Department of Anatomy and Cell Biology, College of Veterinary Medicine, Research Institute for Veterinary Science, \\ Seoul National University, Seoul 08826; ${ }^{2}$ Department of Biochemistry and Molecular Biology, Research Institute of \\ Oral Sciences, College of Dentistry, Gangneung-Wonju National University, Gangneung, Gangwon 25457; \\ ${ }^{3}$ Department of Neurobiology, School of Medicine, Kangwon National University, Chuncheon, Gangwon 24341; \\ ${ }^{4}$ Department of Neurosurgery, Kangnam Sacred Heart Hospital, College of Medicine, Hallym University, \\ Seoul 07441; ${ }^{5}$ Department of Biomedical Sciences, Research Institute for Bioscience and Biotechnology, \\ Hallym University, Chuncheon, Gangwon 24252; ${ }^{6}$ Department of Neurosurgery, Dongtan Sacred Heart \\ Hospital, College of Medicine, Hallym University, Hwaseong, Gyeonggi 18450, Republic of Korea
}

Received January 23, 2016; Accepted February 15, 2017

DOI: $10.3892 / \mathrm{mmr} .2017 .6527$

\begin{abstract}
The present study investigated the protective effects of small ubiquitin-like modifier 1 (SUMO-1) on spinal cord ischemic damage in rabbits. A trans-activator of transcription (Tat)-SUMO-1 fusion protein was prepared, and transient spinal cord ischemia was induced by occlusion of the abdominal aorta for $15 \mathrm{~min}$. Vehicle (glycerol) or $1 \mathrm{mg} / \mathrm{kg}$ Tat-1-SUMO-1 was administered intraperitoneally to the rabbits immediately following ischemia/reperfusion. Administration of Tat-SUMO-1 did not lead to significant alterations in arterial blood gases [partial pressure $(\mathrm{Pa}) \mathrm{CO}_{2}$ and $\mathrm{PaO}_{2}$, $\mathrm{pH}$, or blood glucose levels prior to ischemia, $10 \mathrm{~min}$ after occlusion or $10 \mathrm{~min}$ after reperfusion. Mean arterial pressure was significantly decreased only during occlusion. Motor behaviors were assessed at 24, 48 and $72 \mathrm{~h}$ after ischemia/reperfusion using Tarlov's criteria. Administration of Tat-SUMO-1 significantly improved Tarlov scores $24 \mathrm{~h}$ after ischemia/reperfusion and the number of cresyl violet positive
\end{abstract}

Correspondence to: Professor Soo Young Choi, Department of Biomedical Science, Research Institute for Bioscience and Biotechnology, Hallym University, 1 Hallymdaehak-gil, Chuncheon, Gangwon 24252, Republic of Korea

E-mail: sychoi@hallym.ac.kr

Professor Seung Myung Moon, Department of Neurosurgery, Dongtan Sacred Heart Hospital, College of Medicine, Hallym University, 7 Keunjaebong-gil, Hwaseong, Gyeonggi 18450, Republic of Korea

E-mail: nsmsm@hallym.ac.kr

*Contributed equally

Key words: $\mathrm{Cu}, \mathrm{Zn}$-superoxide dismutase, lipid peroxidation, rabbit, small ubiquitin-like modifier 1, transient spinal cord ischemia neurons was significantly increased in the ventral horn of the spinal cord compared with the vehicle-treated group. However, Tarlov scores were consistently decreased at 48 and $72 \mathrm{~h}$ after ischemia/reperfusion in the Tat-SUMO-1-treated group, and Tarlov scores and the number of cresyl violet positive neurons were not significantly different between the vehicleand Tat-SUMO-1-treated groups after $72 \mathrm{~h}$. Tat-SUMO-1 administration significantly ameliorated a reduction in $\mathrm{Cu}$, $\mathrm{Zn}$-superoxide dismutase activity and an increase in lipid peroxidation $24 \mathrm{~h}$ after ischemia/reperfusion; however, these effects were not present at $72 \mathrm{~h}$. These results suggested that Tat-SUMO-1 may delay, although not protect against, neuronal death by regulating oxidative stress in the ventral horn of the spinal cord and that combination therapy using Tat-SUMO-1 with other compounds may provide a therapeutic approach to decrease neuronal damage.

\section{Introduction}

Paraplegia caused by spinal cord ischemia is a debilitating complication following endovascular intervention for thoracoabdominal aortic aneurysm (1). Interruption of the aorta underneath the renal artery depletes glucose and oxygen supply to the spinal cord and causes neuronal damage in the spinal cord by various mechanisms including glutamate toxicity and increased oxidative stress-induced reactive oxygen species (ROS). Various neuroprotective approaches have been proposed to reduce the neuronal death of the spinal cord, including surgical, physical and chemical methods (2-4).

Small ubiquitin-like modifier (SUMO) is a reversible protein modifier. Numerous key proteins involved in ischemia have been demonstrated to be SUMOylated (5-10). SUMOs consist of three isoforms, and SUMO-1 shares $~ 50 \%$ homology with SUMO-2 and -3, with some overlap in the target proteins. SUMO-1 and SUMO-2/3 are widely expressed in the adult brain $(11,12)$. In the ischemic brain, the SUMO conjugation 
is dramatically increased in the penumbral area following transient focal cerebral ischemia $(6,13)$. In addition, elevated SUMO conjugation has demonstrated neuroprotection against ischemic damage $(12,14)$. However, most studies have focused on the alterations in and effects of SUMO-2/3 levels or conjugation following transient forebrain $(6,13,14)$ or spinal cord ischemia (9).

The brain has a unique structure called the blood-brain barrier, which is the first defense system against toxins in the blood; however, this structure makes it difficult for drugs to access the brain. Previously, cell-penetrating peptides have drawn great attention regarding intracellular access in drug delivery within neuroscience fields (15-17). In previous studies, trans-activator of transcription (Tat)-fusion proteins have been successfully delivered into the brain and spinal cord following administration $(18,19)$.

Therefore, the present study investigated the effects of SUMO-1 on neuronal damage in the ventral horn of the spinal cord using rabbits, as the blood vessels of rabbits are supplied segmentally and there is a lack of collateral circulation $(20,21)$.

\section{Materials and methods}

Experimental animals. Male New Zealand white rabbits $(n=48$, weight, 1.2-1.5 kg) were obtained from the Experimental Animal Center of Cheonan Yonam College (Cheonan, South Korea). They were housed under standard conditions at $22^{\circ} \mathrm{C}$ and $60 \%$ humidity in a 12-h light/dark cycle and with free access to food and water. The handling and care of the animals was in accordance with the NIH Guide for the Care and Use of Laboratory Animals (NIH publication no. 85-23, 1985, revised 1996) (22). Ethical approval was obtained from the Institutional Animal Care and Use Committee of Seoul National University (Seoul, South Korea; approval no. SNU-141021-2).

Tat-SUMO-1 fusion protein expression and purification. Preparation of the Tat expression vector has been described in a previous study (23). Human SUMO-1 was amplified by polymerase chain reaction (PCR) using the following primer sequences: Forward, 5'-CTCGAGATGTCTGACCAGGAG GCA-3' (containing an XhoI restriction site) and reverse, 5'-GGATCCCTAAACTGTTGAATGACCCC-3' (containing a $B a m H I$ restriction site). The resulting PCR products were ligated into the TA vector and cut with XhoI and BamHI. Fragments were subsequently ligated into the Tat expression vector to generate Tat-SUMO-1. Control SUMO-1 was manufactured without the Tat peptide. Recombinant Tat-SUMO-1 plasmid was transformed into $E$. coli BL21 (DE3) and cultured in $0.5 \mathrm{mM}$ isopropyl- $\beta$-D-thio-galactoside (Duchefa Biochemie, Haarlem, Netherlands) at $18^{\circ} \mathrm{C}$ for $>24 \mathrm{~h}$. Harvested cells were lysed by sonication and the Tat-SUMO-1 protein was purified using $\mathrm{Ni}^{2+}$-nitrilotriacetic acid sepharose affinity column and PD-10 column (Qiagen, Inc., Valencia, CA, USA) chromatography to generate a Tat-SUMO-1 protein. Various concentration (0-1,000 mg) of bovine serum albumin (Thermo Fisher Scientific, Waltham, MA, USA) was used as a standard and protein concentration was measured by Bradford assay (24).

Experimental groups and drug treatment. To evaluate the effects of Tat-SUMO-1 against ischemic damage, rabbits were divided into the following groups: Sham-operated, vehicle (glycerol)-treated ischemia-operated and Tat-SUMO-1-treated ischemia-operated groups, at $24 \mathrm{~h}$ and $72 \mathrm{~h}$ following sham operation or ischemia/reperfusion. Tat-SUMO-1 $(1 \mathrm{mg} / \mathrm{kg})$ or an equal volume of glycerol was administered to rabbits immediately following reperfusion by intraperitoneal injection. Arterial blood gases [partial pressure $(\mathrm{Pa}) \mathrm{O}_{2}$ and $\mathrm{PaCO}_{2}$ ], $\mathrm{pH}$ and glucose levels were measured using a GEM Premier 3,000 gas analyzer (Instrumentation Laboratory, Milan, Italy) $10 \mathrm{~min}$ after occlusion of the abdominal aorta and $10 \mathrm{~min}$ after reperfusion. Additionally, mean arterial pressure (MAP) was recorded from the caudal artery by physiography (Gould Instrument Systems, Cleveland, OH, USA) and Ponemah acquisition software version 3.0 (Gould Instrument Systems).

Induction of transient spinal cord ischemia. Rabbits were anesthetized with $2.5 \%$ isoflurane (Baxter, Deerfield, IL, USA) in $67 \% \mathrm{~N}_{2} \mathrm{O}$ and $33 \% \mathrm{O}_{2}$. To spare mesenteric flow to the gut, the abdomen was incised at the ventral midline and the abdominal aorta was isolated beneath the left renal artery, following which it was occluded using an aneurysm clip. Spinal cord ischemia was subsequently induced as described by Kiyoshima et al (25). The aneurysm clip was removed after 15 min of occlusion, and reperfusion was observed from the abdominal aorta. This produced delayed paraplegia within several h of ischemia (26). Free-regulating or normothermic $\left(38.7 \pm 0.3^{\circ} \mathrm{C}\right)$ conditions and a thermometric blanket were used to maintain body temperature, which was monitored with a rectal temperature probe (TR-100; Fine Science Tools, Foster City, CA, USA) throughout the surgical procedure. Once the anesthesia had worn off, rabbits were placed in a thermal incubator (Mirae Medical Industry, Seoul, South Korea) prior to sacrifice. Sham-operated animals underwent the same procedure with the exception of occlusion of the abdominal aorta.

Neurological assessment. To assess neurological function, modified Tarlov criteria were used (27) as follows: 0) no voluntary hind-limb function; i) only perceptible joint movement; ii) active movement but unable to stand; iii) able to stand but unable to walk; or iv) complete normal hind-limb motor function $(28,29)$. Assessments were conducted by two blinded observers for each experiment. Evaluation of control, vehicle-treated, and $1 \mathrm{mg} / \mathrm{kg}$ Tat-SUMO-1-treated groups ( $n=8$ /group) were conducted under identical conditions. Neurological function was examined 24, 48, and $72 \mathrm{~h}$ after reperfusion as it begins to deteriorate 12-24 h after reperfusion, progressing to complete delayed-onset paraplegia by $48 \mathrm{~h}(30,31)$.

Cresyl violet staining in the spinal cord. For histological analysis, animals ( $\mathrm{n}=4 / \mathrm{group}$ ) were anesthetized with $2 \mathrm{~g} / \mathrm{kg}$ urethane (Sigma-Aldrich; Merck KGaA, Darmstadt, Germany) at 24 and $72 \mathrm{~h}$ after ischemia/reperfusion and perfused transcardially with $0.1 \mathrm{M}$ phosphate-buffered saline ( $\mathrm{pH} 7.4$ ), followed by $4 \%$ paraformaldehyde in $0.1 \mathrm{M}$ phosphate-buffer (pH 7.4). The spinal cords were removed and the 5-6th lumbar segments $\left(\mathrm{L}_{5}-\mathrm{L}_{6}\right)$ of the spinal cord were fixed in the same fixative for $4 \mathrm{~h}$. The spinal cord tissues were cryoprotected by incubation with $30 \%$ sucrose overnight, and $30-\mu \mathrm{m}$-thick spinal cord sections were serially cut in the coronal plane 
Table I. Physiological parameters prior to, during and following ischemia.

\begin{tabular}{|c|c|c|c|c|c|}
\hline Group & $\mathrm{pH}$ & $\begin{array}{l}\text { Distal MAP } \\
(\mathrm{mmHg})\end{array}$ & $\begin{array}{c}\mathrm{PaCO}_{2} \\
(\mathrm{mmHg})\end{array}$ & $\begin{array}{c}\mathrm{PaO}_{2} \\
(\mathrm{mmHg})\end{array}$ & Glu (mM) \\
\hline \multicolumn{6}{|l|}{ Pre-ischemia } \\
\hline Control & $7.40 \pm 0.03$ & $85.1 \pm 8.9$ & $37.2 \pm 3.1$ & $102.4 \pm 8.3$ & $6.5 \pm 1.1$ \\
\hline Vehicle & $7.41 \pm 0.02$ & $83.7 \pm 9.3$ & $37.0 \pm 3.4$ & $104.1 \pm 9.5$ & $6.3 \pm 1.1$ \\
\hline Tat-SUMO-1 & $7.42 \pm 0.03$ & $84.3 \pm 9.0$ & $36.8 \pm 2.9$ & $105.3 \pm 9.9$ & $6.7 \pm 1.2$ \\
\hline \multicolumn{6}{|l|}{ Ischemia $10 \mathrm{~min}$} \\
\hline Control & $7.38 \pm 0.04$ & $84.4 \pm 9.5$ & $37.1 \pm 3.4$ & $103.5 \pm 11.6$ & $6.7 \pm 1.2$ \\
\hline Vehicle & $7.37 \pm 0.04$ & $8.9 \pm 2.5^{\mathrm{a}}$ & $37.6 \pm 3.3$ & $100.5 \pm 9.4$ & $7.2 \pm 1.8$ \\
\hline Tat-SUMO-1 & $7.39 \pm 0.03$ & $9.3 \pm 1.9^{\mathrm{a}}$ & $36.9 \pm 4.0$ & $105.2 \pm 9.9$ & $7.0 \pm 1.6$ \\
\hline \multicolumn{6}{|c|}{ Reperfusion $10 \mathrm{~min}$} \\
\hline Control & $7.42 \pm 0.05$ & $86.3 \pm 9.9$ & $36.1 \pm 3.2$ & $101.3 \pm 8.9$ & $6.7 \pm 1.0$ \\
\hline Vehicle & $7.40 \pm 0.04$ & $85.3 \pm 12.1$ & $36.6 \pm 3.7$ & $106.3 \pm 10.5$ & $7.0 \pm 1.9$ \\
\hline Tat-SUMO-1 & $7.39 \pm 0.04$ & $84.7 \pm 9.5$ & $37.0 \pm 3.5$ & $105.9 \pm 11.4$ & $7.1 \pm 1.4$ \\
\hline
\end{tabular}

Data are expressed as the mean \pm standard error ( $\mathrm{n}=16$ /group). ${ }^{\mathrm{a}} \mathrm{P}<0.05$ vs. control group. Tat, trans-activator of transcription; SUMO-1, small ubiquitin-like modifier-1; MAP, mean arterial pressure; $\mathrm{Pa}$, partial pressure; Glu, glucose.

using a cryostat (Leica Microsystems GmbH, Wetzlar, Germany). The sections were stained with cresyl violet acetate as previously described (19).

Counting of cresyl violet-positive neurons at the center of the ventral horn was performed using an analysis system equipped with a computer-based CCD camera (OPTIMAS software version 6.5; CyberMetrics ${ }^{\circledR}$ Corporation, Phoenix, AZ, USA; magnification, x100). The image was converted to a gray-scale image and cresyl violet-positive neurons were automatically selected according to the intensity of cresyl violet staining. Cell counts were averaged from 25 sections at $300-\mu \mathrm{m}$ intervals from each rabbit. Values are reported as a percentage of that obtained from the control groups.

Tissue malondialdehyde (MDA) analyses. The effects of Tat-SUMO-1 on lipid peroxidation in the control, vehicle-, and Tat-SUMO-treated groups ( $\mathrm{n}=4$ /group) were assessed by measuring MDA formation using a 2-thiobarbituric acid reactive substances assay kit (Cayman Chemical Company, Ann Arbor, MI, USA) $24 \mathrm{~h}$ after ischemia/reperfusion. The MDA concentration was determined from a standard curve and expressed in nmol/g of wet tissue. All experiments were conducted in triplicate.

Tissue $C u$, Zn-superoxide dismutase (SOD1) analyses. The enzyme activity of SOD1 was measured using superoxide dismutase assay kits (Cayman Chemical Company) to assess the effects of Tat-SUMO-1 in the control, and vehicle- and Tat-SUMO-1-treated groups ( $n=4 /$ group). Readings were obtained at $550 \mathrm{~nm}$ using a Beckman DU-640B spectrophotometer (Beckman Coulter, Inc., Brea, CA, USA). Final SOD1 activity levels were expressed as units of enzymatic activity/mg protein sample (U/mg protein). One unit of SOD was defined as the amount of enzyme necessary to achieve $50 \%$ dismutation of the superoxide radical. All assays experiments were conducted in triplicate.
Statistical analysis. Multiple comparisons were analyzed by one-way or two-way analysis of variance followed by Bonferroni's post hoc test using GraphPad Prism software verson 5.01 (GraphPad Software, Inc., La Jolla, CA, USA). Data are expressed as the mean \pm standard error. $\mathrm{P}<0.05$ was considered to indicate a statistically significant difference.

\section{Results}

Effect of Tat-SUMO-1 on physiological parameters prior to, during and following ischemia. In the vehicle-treated and Tat-SUMO-1 treated groups, blood gases $\left(\mathrm{PaCO}_{2}\right.$ and $\left.\mathrm{PaO}_{2}\right)$, $\mathrm{pH}$ and glucose levels were not significantly changed $10 \mathrm{~min}$ before induction of ischemia or after reperfusion (Table I). The Tat-SUMO-1 and vehicle-treated groups demonstrated similar patterns of MAP; levels significantly decreased 10 min after occlusion (during ischemia) and were restored to baseline levels $10 \mathrm{~min}$ after reperfusion (Table I).

Effect of Tat-SUMO-1 on Tarlov criteria following spinal cord ischemia. In the control group, all animals exhibited completely normal function $72 \mathrm{~h}$ after the sham operation, and had a neurological score of 4.00. In the vehicle-treated group, numerous animals had no voluntary or barely perceptible joint movement 24, 48 and $72 \mathrm{~h}$ after ischemia/reperfusion, and had a mean neurological score of 0.625 . In the Tat-SUMO-1-treated group, animals could stand; however, could not walk, and had an average neurological score of 2.750 at $24 \mathrm{~h}$ after ischemia/reperfusion. These animals did not stand or move voluntarily, and had an average neurological score of 1.125 at $72 \mathrm{~h}$ after ischemia/reperfusion (Fig. 1).

Effect of Tat-SUMO-1 on neuronal protection following spinal cord ischemia. In the control group, cresyl violet-positive neurons were abundantly detected in the ventral horn of the spinal cord at $24 \mathrm{~h}$ (Fig. 2A) and $72 \mathrm{~h}$ (Fig. 2B) after the sham 

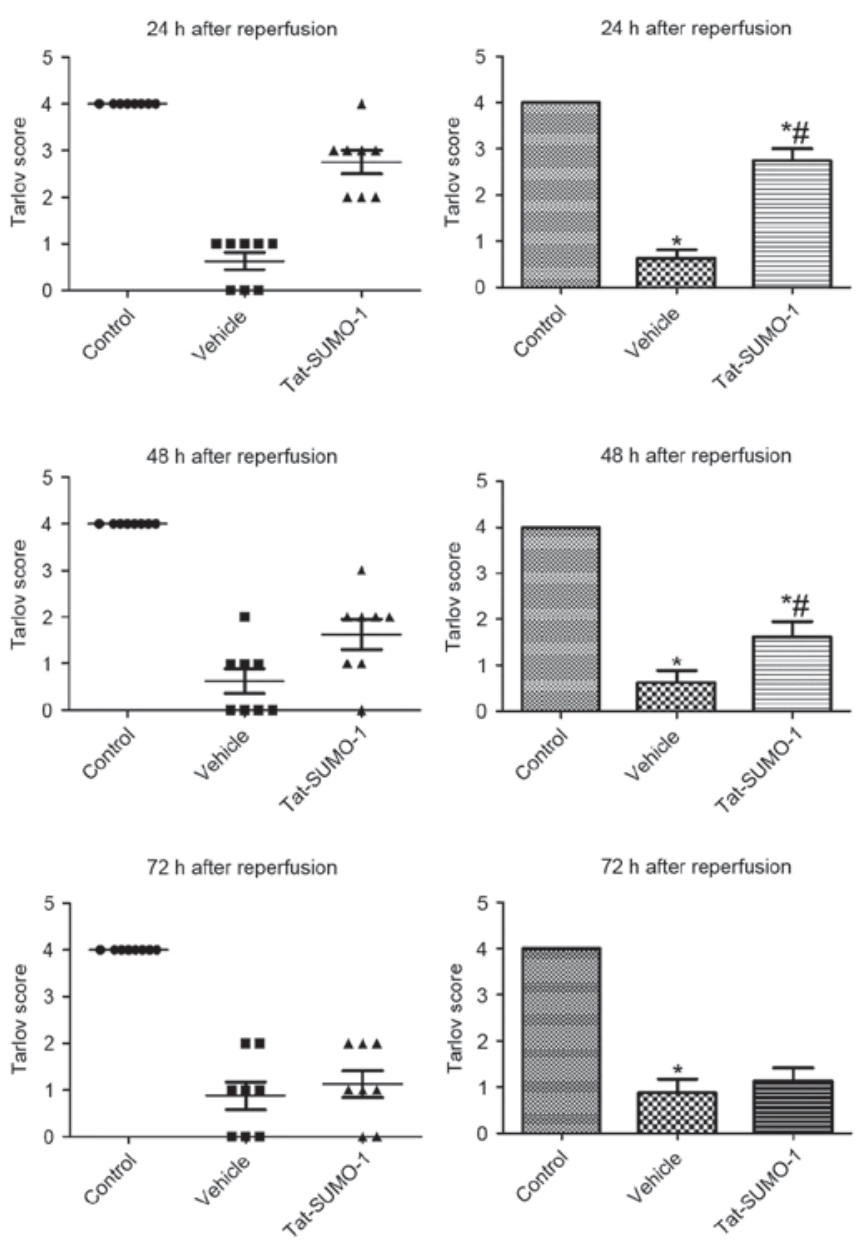

Figure 1. Neurological function scores in each animal and mean scores determined by the modified Tarlov criteria. Control, vehicle-treated and Tat-SUMO-1-treated groups were examined 24, 48 and $72 \mathrm{~h}$ after a sham operation or ischemia/reperfusion. Data are expressed as the mean \pm standard error ( $\mathrm{n}=8$ /group). ${ }^{*} \mathrm{P}<0.05$ vs. control group; ${ }^{\#} \mathrm{P}<0.05$ vs. vehicle-treated group. Tat, trans-activator of transcription; SUMO-1, small ubiquitin-like modifier-1.

operation; however, no significant differences were observed between the two groups. In the vehicle-treated group, cresyl violet-positive neuron counts were decreased in the ventral horn of the spinal cord at $24 \mathrm{~h}$ (Fig. 2C) and $72 \mathrm{~h}$ (Fig. 2D) after ischemia/reperfusion (28.5 and $12.4 \%$ of the control group, respectively, at $24 \mathrm{~h}$ ). In the Tat-SOD1-treated groups, cresyl violet-positive neurons were abundantly detected in the ventral horn of the spinal cord $24 \mathrm{~h}$ after ischemia/reperfusion (Fig. 2E). However, they were markedly reduced in number $72 \mathrm{~h}$ after ischemia/reperfusion (Fig 2F). The proportion of cresyl violet-positive neurons $24 \mathrm{~h}$ and $72 \mathrm{~h}$ after ischemia/reperfusion was $67.5 \%$ and $17.2 \%$ of the control group, respectively, $24 \mathrm{~h}$ after the sham operation (Fig. 2G).

Effect of Tat-SUMO-1 on lipid peroxidation following spinal cord ischemia. In the control group, MDA levels in $\mathrm{L}_{5}-\mathrm{L}_{6}$ spinal cord homogenates were 2.278 and $2.325 \mathrm{nmol} / \mathrm{g}$ protein at 24 and $72 \mathrm{~h}$ after the sham operation, respectively. In the vehicle-treated group, MDA levels were significantly increased compared with the control group to $5.134 \mathrm{nmol} / \mathrm{g}$ protein $24 \mathrm{~h}$ after ischemia/reperfusion $(\mathrm{P}<0.05)$, and were $2.994 \mathrm{nmol} / \mathrm{g}$ protein after $72 \mathrm{~h}$. In the Tat-SUMO-1-treated group, MDA levels in $\mathrm{L}_{5}-\mathrm{L}_{6}$ spinal cord homogenates decreased significantly to $3.244 \mathrm{nmol} / \mathrm{g} 24 \mathrm{~h}$ after ischemia/reperfusion, compared with the vehicle-treated group $(\mathrm{P}<0.05)$. However, compared with the control and vehicle-treated groups, the MDA levels in $\mathrm{L}_{5}-\mathrm{L}_{6}$ spinal cord homogenates increased to $4.264 \mathrm{nmol} / \mathrm{g}$ after $72 \mathrm{~h}$ in the Tat-SUMO-1-treated group ( $\mathrm{P}<0.05$; Fig. 3A).

Effect of Tat-SUMO-1 on SOD1 activity following spinal cord ischemia. In the control groups, SOD1 activity in $\mathrm{L}_{5}-\mathrm{L}_{6}$ spinal cord homogenates was 154.7 and $158.2 \mathrm{U} / \mathrm{mg}$ at 24 and $72 \mathrm{~h}$, respectively, after the sham operation, whereas in the vehicle-treated group, SOD1 activity was significantly decreased compare with the control to 53.4 and $41.2 \mathrm{U} / \mathrm{mg}$ after 24 and $72 \mathrm{~h}$, respectively $(\mathrm{P}<0.05)$. In the Tat-SUMO-1-treated group, SOD1 activity was significantly increased to $127.3 \mathrm{U} / \mathrm{mg}$ after $24 \mathrm{~h}$, compared with the vehicle-treated group $(\mathrm{P}<0.05)$. However, SOD1 activity in the Tat-SUMO-1-treated group was significantly decreased to $59.3 \mathrm{U} / \mathrm{mg}$ at $72 \mathrm{~h}$, compared with Tat-SUMO-1-treated group at $24 \mathrm{~h}$ (Fig. 3B).

\section{Discussion}

SUMOylation may be part of an endogenous neuroprotective response to cellular stress, particularly in brain ischemia $(7,8,12)$. There have been conflicting reports regarding of SUMOylation by SUMO-1 and SUMO-2/3 following ischemic damage. Shao et al (32) demonstrated that under hypoxia, SUMO-1 protein and mRNA expression levels were markedly increased in the brain and heart (32). Cimarosti et al (5) revealed that SUMO-1 and SUMO-2/3 levels were markedly increased after 6 and $24 \mathrm{~h}$ in the striatal infarct area. However, there have been reports that SUMO-1 conjugation is not altered in the ischemic hippocampus (5) or spinal cord (9). Under normal conditions, there is a large pool of free SUMO-2 and -3, and limited SUMO-1 (33). The present study examined the effects of Tat-SUMO-1 following ischemic damage in the rabbit spinal cord. The administration of Tat-SUMO-1 did not have any effect on blood biochemical parameters including $\mathrm{pH}$, blood glucose, and the arterial blood gases $\mathrm{PaCO}_{2}$ and $\mathrm{PaO}_{2}$, prior to or following transient spinal cord ischemia. Significant decreases in MAP levels in the caudal artery were observed in vehicle- and Tat-SUMO-1-treated groups $10 \mathrm{~min}$ after ischemia, which thereafter returned to normal levels in the two groups. This result suggested that the transient spinal cord ischemia is completely induced in the two groups and that Tat-SUMO-1 has no effect on blood gases or pressure prior to or following ischemia/reperfusion.

The present study observed alterations in hind limb behaviors on the basis of the Tarlov criteria (27). Administration of Tat-SUMO-1 significantly ameliorated the ischemia-induced reduction in Tarlov score $24 \mathrm{~h}$ after ischemia/reperfusion. However, the Tarlov score was significantly decreased $72 \mathrm{~h}$ after ischemia/reperfusion, similar to in the vehicle-treated group. Morphological evidence based on cresyl violet histochemistry supported the behavioral results; positively-stained neurons were abundantly detected in the ventral horn of the spinal cord $24 \mathrm{~h}$ after ischemia/reperfusion; however, the number significantly decreased after $72 \mathrm{~h}$. This result suggested that Tat-SUMO-1 does not protect against 

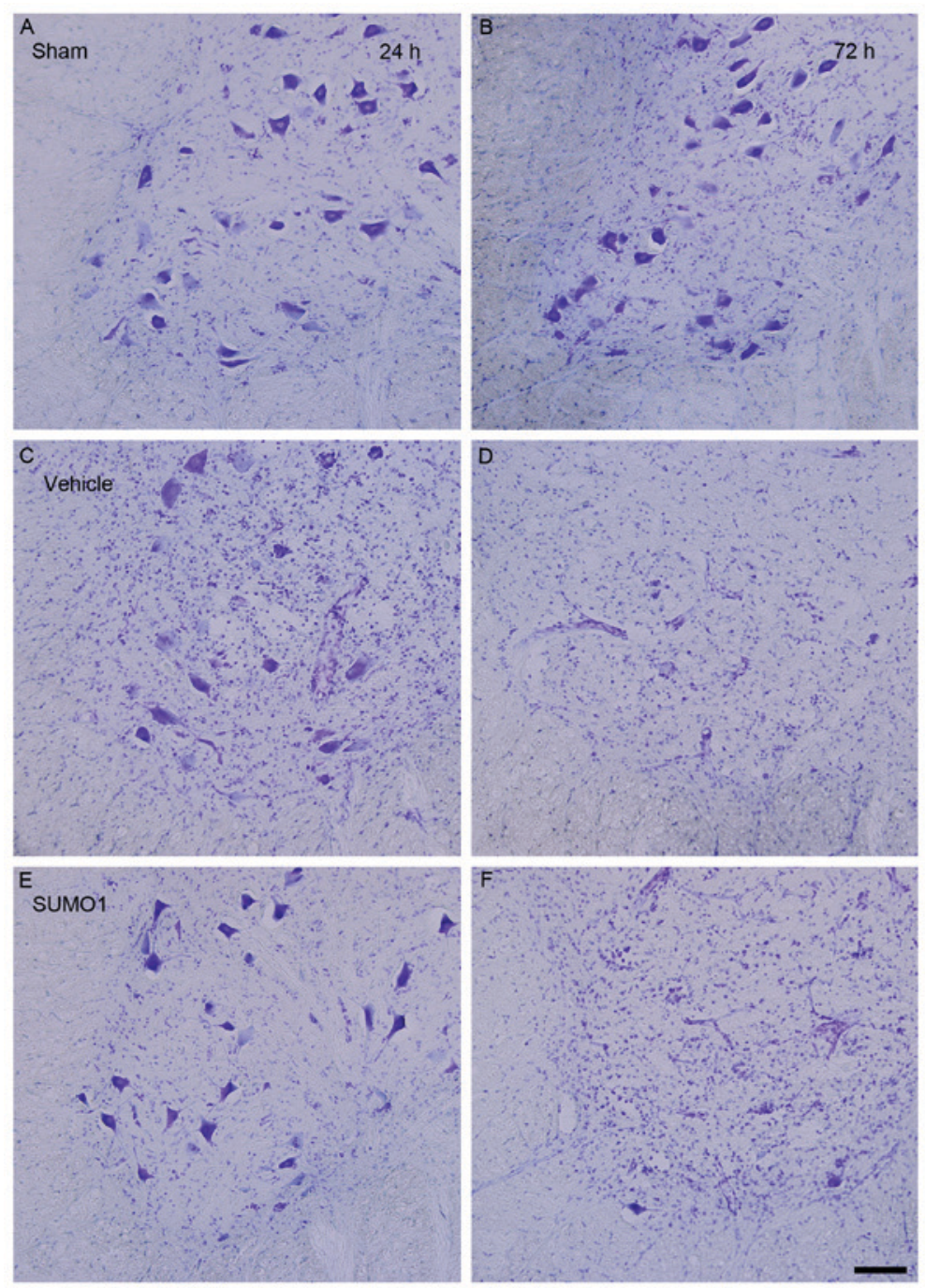

G

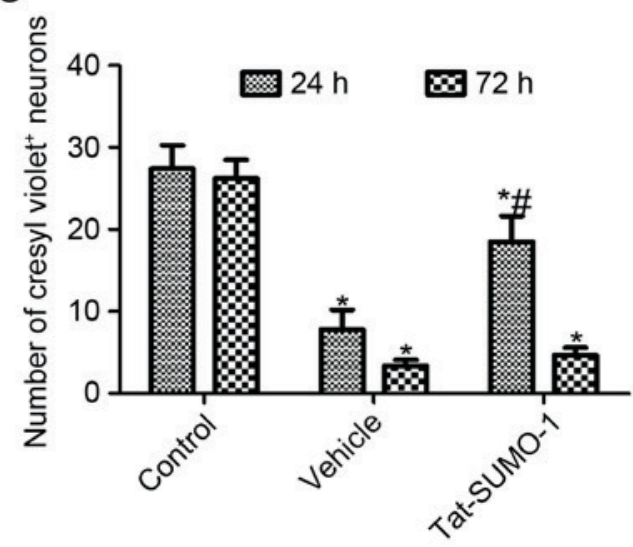

Figure 2. Histochemical analysis. Cresyl violet staining of surviving neurons in the 5-6th lumbar segments of the spinal cord in the ventral horn of the different groups: (A) $24 \mathrm{~h}$ control and (B) $72 \mathrm{~h}$ control; (C) $24 \mathrm{~h}$ vehicle-treated and (D) $72 \mathrm{~h}$ vehicle-treated and (E) $24 \mathrm{~h}$ Tat-SUMO-1-treated and (F) $72 \mathrm{~h}$ Tat-SUMO-1-treated groups after the sham operation or ischemia/reperfusion. In the control group, abundant cresyl violet-positive neurons were detected 24 and $72 \mathrm{~h}$ after ischemia/reperfusion; however, positively stained neurons were reduced in the vehicle-treated group at both time points. In the Tat-SUMO-1-treated group, there were increased positively stained neurons $24 \mathrm{~h}$ after ischemia/reperfusion; however, numbers reduced after $72 \mathrm{~h}$. Scale bar $=100 \mu \mathrm{m}$. (G) Quantification of the mean number of cresyl violet-positive neurons per section of each group (n=4/group). Data are expressed as the mean \pm standard error of mean ( $\mathrm{n}=4$ /group). ${ }^{*} \mathrm{P}<0.05$ vs. control group; ${ }^{*} \mathrm{P}<0.05$ vs. vehicle-treated group. Tat, trans-activator of transcription; SUMO-1, small ubiquitin-like modifier-1.
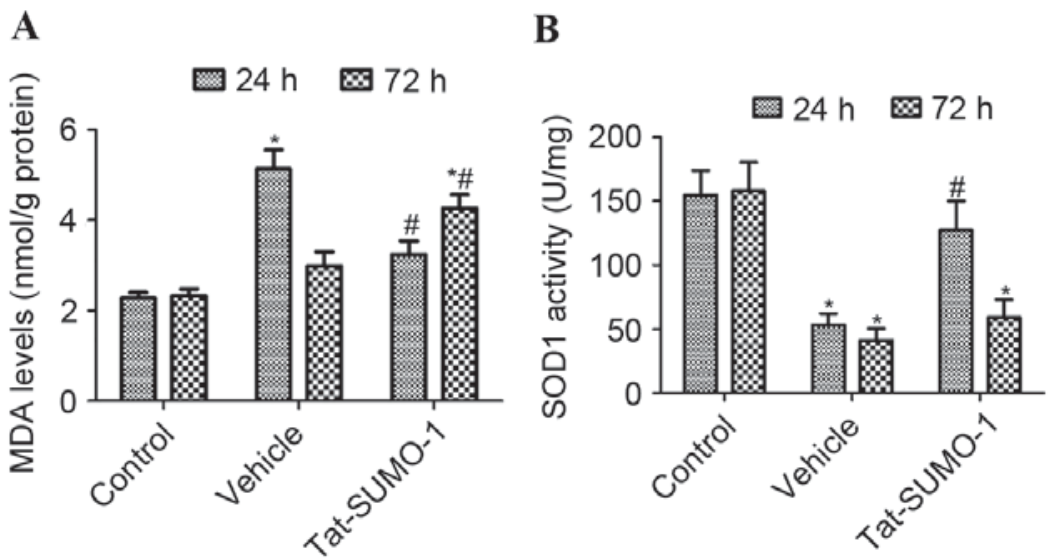

Figure 3. Effect of Tat-SUMO-1 on lipid peroxidation and SOD1 levels following spinal cord ischemia. (A) Levels of MDA and (B) activity of SOD1 in the 5-6th lumbar segments of the spinal cord samples from the control, vehicle-treated and Tat-SUMO-1-treated groups 24 and $72 \mathrm{~h}$ after the sham operation or ischemia/reperfusion. Data are expressed as the mean \pm standard error $\left(\mathrm{n}=4 /\right.$ group). ${ }^{*} \mathrm{P}<0.05$ vs. control group; ${ }^{\text {}} \mathrm{P}<0.05$ vs. vehicle-treated group. MDA, malondialdehyde; SOD1, Cu, Zn-superoxide dismutase; Tat, trans-activator of transcription; SUMO-1, small ubiquitin-like modifier-1. 
neuronal damage following spinal cord ischemia, although it transiently delays it. There have been reports that overexpression of SUMO-1 significantly reduces damage from oxygen-glucose deprivation (34) and rescues cardiac function in a mouse and swine model of heart failure $(35,36)$. In addition, knockdown of SUMO-1 by small interfering- or short hairpin RNA increased the susceptibility of SHSY5Y human neuroblastoma cells and cultured cortical neurons (34) and accelerated the deterioration of cardiac function $(35,36)$. The discrepancies in the effects of SUMO-1 between the present and other studies may be associated with the delivery methods of SUMO-1. The present study directly delivered SUMO-1 by using the Tat-SUMO-1 fusion protein; however, others administered SUMO-1 via genetic engineering with viral vectors. These results suggested that transient treatment with SUMO-1 protein did not induce neuroprotection against ischemic damage in the spinal cord; however, delayed neuronal damage.

The mechanisms underlying this result were not fully elucidated in this study. The present study focused on lipid peroxidation and SOD1 because SUMOylation is known to be increased following exposure to various stressors, including strong oxidative stress (37). The present study demonstrated that lipid peroxidation was significantly increased $24 \mathrm{~h}$ after ischemia/reperfusion, whereas SOD1 activity was decreased. This result was supported by previous studies, which demonstrated that spinal cord ischemia increases lipid peroxidation and the subsequent inactivation and consumption of SOD1 in the spinal cord (38-40). A previous study reported that at $\mathrm{H}_{2} \mathrm{O}_{2}$ concentrations of $1 \mathrm{mM}$ and below, SUMO-1, -2, and -3 conjugates were almost completely lost (37). In the present study, administration of Tat-SUMO-1 ameliorated the increases in lipid peroxidation and depletion of SOD1 levels $24 \mathrm{~h}$ after ischemia/reperfusion in the spinal cord. This result was supported by a previous study, which revealed that SUMO-1 conjugation resulted in a decrease in intracellular ROS generation (41). In addition, inhibition of endogenous SUMOylation increased ROS production from Nox5 human embryonic kidney cells, human vascular smooth muscle cells and neutrophils (42). Additionally, administration of antioxidants was previously demonstrated to reduce cisplatin-induced SUMOylation (43). However, these effects in the present study were not maintained at $72 \mathrm{~h}$ after ischemia/reperfusion. At this time point, lipid peroxidation and SOD1 levels were demonstrated to be similar to those in the vehicle-treated group. This result suggested that administration of SUMO-1 may improve neuronal damage transiently by regulation of antioxidant or lipid peroxidation during early ischemia. SUMO-1 may facilitate neuroprotection against ischemic damage, in combination with antioxidants, calcium modulators, or other therapeutic compounds in the spinal cord. It has been reported that pET-glutathione transferase-SUMO-metallothionein fusion proteins improved memory impairments and increased lipid peroxidation in a chemically-induced ageing model (44).

In conclusion, the present study demonstrated that Tat-SUMO-1 administration delays neuronal death from ischemic damage in the spinal cord by regulating oxidative stress. These results suggested that Tat-SUMO-1 treatment, in combination with antioxidants, calcium modulators or other compounds, may provide a therapeutic approach to reduce neuronal damage.

\section{Acknowledgements}

The present study was supported by Basic Science Research Program through the National Research Foundation of Korea funded by the Ministry of Education (grant no. NRF-2014R1A1A2056492) and a Priority Research Centers Program grant from the National Research Foundation (grant no. NRF-2009-0093812) funded by the Ministry of Science, ICT \& Future Planning in the Republic of Korea.

\section{References}

1. Schepens MA, Heijmen RH, Ranschaert W, Sonker U and Morshuis WJ: Thoracoabdominal aortic aneurysm repair: Results of conventional open surgery. Eur J Vasc Endovasc Surg 37: 640-645, 2009

2. Cambria RP, Davison JK, Carter C, Brewster DC, Chang Y, Clark KA and Atamian S: Epidural cooling for spinal cord protection during thoracoabdominal aneurysm repair: A five-year experience. J Vasc Surg 31: 1093-1102, 2000.

3. Coselli JS, LeMaire SA, Köksoy C, Schmittling ZC and Curling PE: Cerebrospinal fluid drainage reduces paraplegia after thoracoabdominal aortic aneurysm repair: Results of a randomized clinical trial. J Vasc Surg 35: 631-639, 2002.

4. Safi HJ, Miller CC III, Huynh TT, Estrera AL, Porat EE, Winnerkvist AN, Allen BS, Hassoun HT and Moore FA: Distal aortic perfusion and cerebrospinal fluid drainage for thoracoabdominal and descending thoracic aortic repair: Ten years of organ protection. Ann Surg 238: 372-381, 2003.

5. Cimarosti H, Lindberg C, Bomholt SF, Rønn LC and Henley JM: Increased protein SUMOylation following focal cerebral ischemia. Neuropharmacology 54: 280-289, 2008.

6. Yang W, Sheng H, Warner DS and Paschen W: Transient focal cerebral ischemia induces a dramatic activation of small ubiquitin-like modifier conjugation. J Cereb Blood Flow Metab 28: 892-896, 2008.

7. Lee YJ and Hallenbeck JM: SUMO and ischemic tolerance. Neuromolecular Med 15: 771-781, 2013.

8. Silveirinha V, Stephens GJ and Cimarosti H: Molecular targets underlying SUMO-mediated neuroprotection in brain ischemia. J Neurochem 127: 580-591, 2013.

9. Wang Z, Wang R, Sheng H, Sheng SP, Paschen W and Yang W: Transient ischemia induces massive nuclear accumulation of SUMO2/3-conjugated proteins in spinal cord neurons. Spinal Cord 51: 139-143, 2013.

10. Yang W and Paschen W: SUMO proteomics to decipher the SUMO-modified proteome regulated by various diseases. Proteomics 15: 1181-1191, 2015.

11. Zhang FP, Mikkonen L, Toppari J, Palvimo JJ, Thesleff I and Jänne OA: Sumo-1 function is dispensable in normal mouse development. Mol Cell Biol 28: 5381-5390, 2008

12. Lee YJ, Mou Y, Maric D, Klimanis D, Auh S and Hallenbeck JM: Elevated global SUMOylation in Ubc9 transgenic mice protects their brains against focal cerebral ischemic damage. PLoS One 6: e25852, 2011.

13. Hochrainer K, Jackman K, Anrather J and Iadecola C: Reperfusion rather than ischemia drives the formation of ubiquitin aggregates after middle cerebral artery occlusion. Stroke 43: 2229-2235, 2012

14. Cimarosti H, Ashikaga E, Jaafari N, Dearden L, Rubin P, Wilkinson KA and Henley JM: Enhanced SUMOylation and SENP-1 protein levels following oxygen and glucose deprivation in neurones. J Cereb Blood Flow Metab 32: 17-22, 2012.

15. Kilic E, Kilic U and Hermann DM: TAT fusion proteins against ischemic stroke: Current status and future perspectives. Front Biosci 11: 1716-1721, 2006.

16. Fonseca SB, Pereira MP and Kelley SO: Recent advances in the use of cell-penetrating peptides for medical and biological applications. Adv Drug Deliv Rev 61: 953-964, 2009.

17. Stalmans S, Bracke N, Wynendaele E, Gevaert B, Peremans K, Burvenich C, Polis I and De Spiegeleer B: Cell-penetrating peptides selectively cross the blood-brain barrier in vivo. PLoS One 10: $\mathrm{e} 0139652,2015$. 
18. Eum WS, Kim DW, Hwang IK, Yoo KY, Kang TC, Jang SH, Choi HS, Choi SH, Kim YH, Kim SY, et al: In vivo protein transduction: Biologically active intact pep-1-superoxide dismutase fusion protein efficiently protects against ischemic insult. Free Radic Biol Med 37: 1656-1669, 2004.

19. Kim W, Kim DW, Jeong HJ, Yoo DY, Jung HY, Nam SM, Kim JH, Choi JH, Won MH, Yoon YS, et al: Tat-DJ-1 protects neurons from ischemic damage in the ventral horn of rabbit spinal cord via increasing antioxidant levels. Neurochem Res 39: 187-193, 2014

20. DeGirolami U and Zivin JA: Neuropathology of experimental spinal cord ischemia in the rabbit. J Neuropathol Exp Neurol 41: 129-149, 1982

21. Weir CJ, Zivin JA and Lyden PD: Inter-relationships between spinal cord blood flow, neuronal death and neurological function in rabbit spinal cord ischemia. Brain Res 946: 43-51, 2002.

22. National Research Council: Guide for the Care and Use of Laboratory Animals. 7th edition. National Academy Press, Washington DC, 1996.

23. Kwon HY, Eum WS, Jang HW, Kang JH, Ryu J, Ryong Lee B, Jin LH, Park J and Choi SY: Transduction of $\mathrm{Cu}, \mathrm{Zn}$-superoxide dismutase mediated by an HIV-1 Tat protein basic domain into mammalian cells. FEBS Lett 485: 163-167, 2000.

24. Bradford MA: A rapid and sensitive method for the quantification of microgram quantities of protein utilizing the principle of protein-dye binding. Anal Biochem 72: 248-254, 1976.

25. Kiyoshima T, Fukuda S, Matsumoto M, Iida Y, Oka S, Nakakimura K and Sakabe T: Lack of evidence for apoptosis as a cause of delayed onset paraplegia after spinal cord ischemia in rabbits. Anesth Analg 96: 839-846, 2003.

26. Murakami H, Tsukube T, Kawanishi Y and Okita Y: Transcranial myogenic motor-evoked potentials after transient spinal cord ischemia predicts neurologic outcome in rabbits. J Vasc Surg 39: 207-213, 2004

27. Tarlov IM: Spinal cord compression; mechanism of paralysis and treatment. In: Thomas CC (ed). Springfield, Illinois, pp147, 1957.

28. Jacobs TP, Kempski O, McKinley D, Dutka AJ, Hallenbeck JM and Feuerstein G: Blood flow and vascular permeability during motor dysfunction in a rabbit model of spinal cord ischemia. Stroke 23: 367-373, 1992.

29. Huang Y, Xie K, Li J, Xu N, Gong G, Wang G, Yu Y, Dong H and Xiong L: Beneficial effects of hydrogen gas against spinal cord ischemia-reperfusion injury in rabbits. Brain Res 1378: 125-136, 2011.

30. Moore WM Jr and Hollier LH: The influence of severity of spinal cord ischemia in the etiology of delayed-onset paraplegia. Ann Surg 213: 427-432, 1991.

31. Wisselink W, Patetsios P, Panetta TF, Ramirez JA, Rodino W, Kirwin JD and Zikria BA: Medium molecular weight pentastarch reduces reperfusion injury by decreasing capillary leak in an animal model of spinal cord ischemia. J Vasc Surg 27: 109-116, 1998.

32. Shao R, Zhang FP, Tian F, Anders Friberg P, Wang X, Sjöland H and Billig H: Increase of SUMO-1 expression in response to hypoxia: Direct interaction with HIF-1alpha in adult mouse brain and heart in vivo. FEBS Lett 569: 293-300, 2004.
33. Saitoh $\mathrm{H}$ and Hinchey J: Functional heterogeneity of small ubiquitin-related protein modifiers SUMO-1 versus SUMO-2/3. J Biol Chem 275: 6252-6258, 2000.

34. Lee YJ, Castri P, Bembry J, Maric D, Auh S and Hallenbeck JM: SUMOylation participates in induction of ischemic tolerance. J Neurochem 109: 257-267, 2009.

35. Kho C, Lee A, Jeong D, Oh JG, Chaanine AH, Kizana E, Park WJ and Hajjar RJ: SUMO1-dependent modulation of SERCA2a in heart failure. Nature 477: 601-605, 2011.

36. Tilemann L, Lee A, Ishikawa K, Aguero J, Rapti K, Santos-Gallego C, Kohlbrenner E, Fish KM, Kho C and Hajjar RJ: SUMO-1 gene transfer improves cardiac function in a large-animal model of heart failure. Sci Transl Med 5: 211ra159, 2013.

37. Bossis G and Melchior F: Regulation of SUMOylation by reversible oxidation of SUMO conjugating enzymes. Mol Cell 21: 349-357, 2006.

38. Kim W, Kim DW, Yoo DY, Chung JY, Hwang IK, Won MH, Choi SY, Jeon SW, Jeong JH, Hwang HS and Moon SM: Neuroprotective effects of PEP-1-Cu,Zn-SOD against ischemic neuronal damage in the rabbit spinal cord. Neurochem Res 37: 307-313, 2012.

39. Gürer B, Kertmen H, Kasim E, Yilmaz ER, Kanat BH, Sargon MF, Arikok AT, Ergüder BI and Sekerci Z: Neuroprotective effects of testosterone on ischemia/reperfusion injury of the rabbit spinal cord. Injury 46: 240-248, 2015.

40. Jung HY, Kim DW, Yim HS, Yoo DY, Kim JW, Won MH, Yoon YS, Choi SY and Hwang IK: Heme oxygenase-1 protects neurons from ischemic damage by upregulating expression of $\mathrm{Cu}, \mathrm{Zn}$-superoxide dismutase, catalase, and brain-derived neurotrophic factor in the rabbit spinal cord. Neurochem Res 41: 869-879, 2016

41. Kim HJ, Yun J, Lee J, Hong H, Jeong J, Kim E, Bae YS and Lee KJ: SUMO1 attenuates stress-induced ROS generation by inhibiting NADPH oxidase 2. Biochem Biophys Res Commun 410: 555-562, 2011.

42. Pandey D, Chen F, Patel A, Wang CY, Dimitropoulou C, Patel VS, Rudic RD, Stepp DW and Fulton DJ: SUMO1 negatively regulates reactive oxygen species production from NADPH oxidases. Arterioscler Thromb Vasc Biol 31: 1634-1642, 2011.

43. Guo C, Wei Q, Su Y and Dong Z: SUMOylation occurs in acute kidney injury and plays a cytoprotective role. Biochim Biophys Acta 1852: 482-489, 2015.

44. Huang Y, Su Z, Li Y, Zhang Q, Cui L, Su Y, Ding C, Zhang M, Feng C, Tan Y, et al: Expression and purification of glutathione transferase-small ubiquitin-related modifier-metallothionein fusion protein and its neuronal and hepatic protection against D-galactose-induced oxidative damage in mouse model. J Pharmacol Exp Ther 329: 469-478, 2009. 